\title{
Influence of Different Teenagers on Attitudes and Behaviors of Their Parents in Physical Education
}

\author{
Guo Jiao Wang \\ Weifang Medical University, China \\ Email: wangguojiao578@126.com
}

Keywords: Teenagers; Parents; Attitudes in Physical Education; Behaviors in Physical Education.

\begin{abstract}
Objective: To explore influence of different teenagers on attitudes and behaviors of their parents in Physical Education. Methods: To investigate attitudes and behaviors of 99 youths' parents in Physical Education using self-design questionnaires and to analyze valid datas using SPSS for Windows 16.0. Results: The main effect of teenagers with different genders to their parents' attitudes and behaviors in Physical Education wasn't significant $(\mathrm{P}>0.05)$; the main effect of teenagers with different grades to their parents' attitudes was significant $(\mathrm{F}=5.657, \mathrm{p}<0.05 ; \mathrm{F}=12.924, \mathrm{p}<0.01)$; the interaction of teenagers with different genders and grades to their parents' attitudes in Physical Education was significant $(\mathrm{F}=3.777, \mathrm{p}<0.05 ; \mathrm{F}=9.158, \mathrm{p}<0.01)$; the main effect of teenagers with different grades to fathers' behaviors in Physical Education was significant( $\mathrm{F}=4.429, \mathrm{p}<0.05)$, however, that to mothers' behaviors wasn't significant $(\mathrm{F}=2.914, \mathrm{p}>0.05)$. Conclusion: Teenagers with different genders and grades had a different impact on their parental attitudes and behaviors in Physical Education.
\end{abstract}

\section{Introduction}

With the development China's social economy and the improvement of people's living standard, sports have been drawing people's increasing attention as a kind of wealth and culture.Since the 1990s, lifelong sports have become an orientation of PE reform and education. Lifelong sports are mainly implemented through the following two approaches: The first approach is to take school PE as a breakthrough point as lifelong sports and school PE are inseparable and the school PE as the basis of lifelong sports plays an important connecting role between the preceding and the following in the system of lifelong sports. In the field of school PE, in view of the current situation of students' physical fitness being unsatisfactory on the whole, sports attitudes and behaviors have become a research hot subject in PE and pedagogy and currently quite a few studies [1-2] on the attitudes and behaviors of teenagers and college students about sports have analyzed and explored the students' sports status and the causes and provided effective suggestions for the smooth development of school sports. The second approach is to take adult sports as a breakthrough point. To guide adults in their sports attitudes and behaviors is the key to mobilizing national fitness campaign and implementing lifelong sports. Now some researchers have been conducted to analyze and investigate [3-5]the adults sports attitudes and behaviors but the age spans included in the survey vary greatly and are not unified (ages ranging from 20 to 60) and the descriptive study dominates the researches. Based on the existing literature I draw the following conclusions: in terms of groups studied, students are the focus of sports attitudes and behaviors while the sports study on adults draw less attention, and in particular the influencing factors of adult sports tendency are studied even less. In terms of exploration direction, in the exploration of the influencing factors of sports attitudes and behavior, influences from parents on children are being paid more and more attention[6-8], and less attention is being paid to the influences from children on their parents 's sports attitudes and behaviors. In view of the above reasons, this study explores and analyzes the influences of teenagers on their parents' sports attitudes and behaviors, with the children and their parents as the subjects. 


\section{Research Subjects and Methods}

Research Subjects. This study takes teenagers and their parents as research subjects, using the method of convenience sampling like snowballing. Parents whose children are educated in ordinary middle schools in rural and urban areas in Weifang City, Yantai City and Dezhou City in Shangdong Province are selected and 110 questionnaires (parents version) are distributed and 99 valid copies of questionnaires have been recovered. In the valid questionnaires, the basic information of the teenagers is as follows: 34 students are boys, 65 girls; 50 students are senior middle school students and 49 junior middle school students.

Research Tools. The self-designed questionnaire concerning the sports attitudes and behaviors of parents of teenagers is adopted. The questionnaire consists of 15 items, of which 12 items are for testing sports attitudes , and 3 for testing sports behaviors.5-grade scoring method for each item is adopted and the lower the scores for the sports attitudes, the more active the attitudes are. The scores for sports behaviors are the product of the evaluation of the times of sports activities, and their time duration and degree and the higher the scores the higher degree of sports participation. Through testing, the questionnaire proves to be reliable and valid and its internal consistent reliability ranges from 0.83 to 0.89 .

Research Procedures. The questionnaires for parents are bound and their items for father and mother are arranged in different sequences and parents are asked to answer questions respectively. The 99 valid copies of the questionnaire are statistically processed with SPSS for Windows 16.0, and such methods as t testing, and multivariate analysis variance are used to explore the effects of types of teenagers on the sports attitudes and behaviors of their parents.

\section{Results}

The Status of Sports Attitudes and Behaviors of Parents of Different Types of Teenagers. The relevant testing results show that the correlation of both parents' sports attitudes is significant $(\mathrm{r}=0.824, \mathrm{p}>0.01)$ and the correlation of both parents' sports behaviors is also significant $(\mathrm{r}=0.54$, $\mathrm{p}<0.01)$ and the correlation of their attitudes is obviously higher than that of behavioral correlation .

Testing finds that for sports attitudes, the influences of the gender of teenagers on the sports attitudes of both parents are not obvious $(\mathrm{p}<0.05)$; but when teenagers are in different grades ( junior middle school period or senior middle school period), the differences of sports attitudes between father and mother are marked $(\mathrm{t}=1.982, \mathrm{p}<0.05 ; \mathrm{t}=2.761, \mathrm{p}<0.01)$, and the sports attitudes of parents of junior middle school students are more active than those of parents of senior middle school students.

For sports behaviors, the influences of the gender of teenagers on the sports behaviors of their parents are not obvious ( $\mathrm{p}>0.05)$; but when teenager are in different grades (junior middle school period or senior middle school period ), the gender of teenagers affects the sports behaviors of their parents differently and the scores of the father of a senior middle school student are clearly lower than those of a junior middle school student $(\mathrm{t}=-2.322, \mathrm{p}<0.05)$, and the sports behaviors of a mother do not experience a marked difference with the changes of grades of her child $(\mathrm{t}=-1.887, \mathrm{p}>0.05)$. 
Table 1 Status of Sports Attitudes and Behaviors of Parents of Different Types of Teenagers

\begin{tabular}{|c|c|c|c|c|c|}
\hline type & category & $\begin{array}{c}\text { father's sports } \\
\text { attitudes }\end{array}$ & $\begin{array}{l}\text { mother's sports } \\
\text { attitudes }\end{array}$ & $\begin{array}{l}\text { father's sports } \\
\text { behaviors }\end{array}$ & $\begin{array}{c}\text { mother's } \\
\text { sports } \\
\text { behaviors }\end{array}$ \\
\hline \multirow[b]{2}{*}{ Gender $(X \pm \mathrm{s})$} & male & $2.22 \pm 0.80$ & $2.34 \pm 0.96$ & $19.44 \pm 20.39$ & $13.65 \pm 14.06$ \\
\hline & female & $2.44 \pm 0.79$ & $2.49 \pm 0.77$ & $14.20 \pm 17.17$ & $11.63 \pm 15.39$ \\
\hline \multirow{3}{*}{ 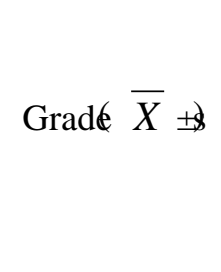 } & $t$ & -1.317 & -0.842 & 1.351 & 0.637 \\
\hline & $\begin{array}{l}\text { senior middle school } \\
\text { junior middle school }\end{array}$ & $\begin{array}{l}2.52 \pm 0.71 \\
2.21 \pm 0.86\end{array}$ & $\begin{array}{c}2.66 \pm 0.78 \\
2.21 \pm 0.84\end{array}$ & $\begin{array}{l}11.82 \pm 12.57 \\
20.27 \pm 22.22\end{array}$ & $\begin{array}{c}9.56 \pm 14.3 \\
15.14 \pm 15.04\end{array}$ \\
\hline & $t$ & $1.982^{*}$ & $2.761^{* *}$ & -2.322 & -1.887 \\
\hline
\end{tabular}

Note: ${ }^{*} \mathrm{p}<0.05,{ }^{*}{ }^{*} \mathrm{p}<0.01$ ( similarly hereinafter)

\section{Effects of Different Types of Teenagers on Their Parents' Sports Attitudes.}

Table 2 the Effects of the Type of Teenagers on Father's Sports Attitudes

\begin{tabular}{cccccc}
\hline Source & Sum of Squares & df & Mean Square & $F$ & $p$ \\
\hline gender A & 0.520 & 1 & 0.520 & 0.865 & 0.355 \\
grade B & 3.398 & 1 & 3.398 & 5.657 & 0.019 \\
A*B & 2.269 & 1 & 2.269 & 3.777 & 0.045 \\
Error & 57.072 & 95 & 0.601 & & \\
\hline
\end{tabular}

To explore the specific effects of the different types of teenagers (gender A and grade B are both dichotomous variables) on their parents' sports attitudes, this study adopts the method of multivariate analysis of variance to analyze the major effects and the interactive effects that affect parents' sports attitudes. It has been found that the major effects of the gender of teenagers on parents are not striking $(p>0.05)$; when teenagers are in different grades( junior or senior middle schools), the major effects on the sports attitudes of their parents (father and mother)are striking ( $\mathrm{F}=5.657, \mathrm{p}<0.05$; $\mathrm{F}=12.924, \mathrm{p}<0.01$ ), and the interactive effects of the gender and grades of teenagers are also $\operatorname{striking}(\mathrm{F}=3.777, \mathrm{p}<0.05 ; \mathrm{F}=9.158, \mathrm{p}<0.01)$.

Table 3. Effects of the Types of Teenagers on the Sports Behaviors of Their Mothers

\begin{tabular}{cccccc}
\hline Source & Sum of Squares & df & Mean Square & $F$ & $p$ \\
\hline $\begin{array}{c}\text { gender A } \\
\text { grade B }\end{array}$ & 0.047 & 1 & 0.047 & 0.077 & 0.782 \\
$\mathrm{~A} * \mathrm{~B}$ & 7.860 & 1 & 7.860 & 12.924 & 0.001 \\
Error & 5.570 & 1 & 5.570 & 9.158 & 0.003 \\
\hline & 57.778 & 95 & 0.608 & - & - \\
\hline
\end{tabular}


Effects of Different Types of Teenagers on Their Parents' Sports Behaviors.

Table 4. Effect of the Type of Teenagers on the Sports Behaviors of Their Fathers

\begin{tabular}{cccccc}
\hline \multirow{2}{*}{ Source } & Sum of Squares & df & Mean Square & $F$ & $p$ \\
\hline \hline gender A & 358.508 & 1 & 358.508 & 1.097 & 0.298 \\
grade B & 1447.684 & 1 & 1447.684 & 4.429 & 0.038 \\
A*B & 11.672 & 1 & 11.672 & 0.036 & 0.851 \\
Error & 31051.92 & 95 & 326.862 & - & - \\
\hline
\end{tabular}

By adopting the method of multivariate analysis of variance to analyze the major effects and the interactive effects that affect the sports behaviors of parents, it has been found that the effects of the gender of teenagers on the sports behaviors of their parents are not striking $(p>0.05)$; when teenagers are in different grades( junior or senior middle schools), the major effects on the sports attitudes of father are striking $(\mathrm{F}=4.429, \mathrm{p}<0.05)$ while the major effects on the sports attitudes of mothers are not striking $(\mathrm{F}=2.914, \mathrm{p}>0.05)$; and the interactive effects of teenagers' gender and grade are also not $\operatorname{striking}(\mathrm{p}>0.05)$.

Table 5. Effect of the Type of Teenagers on the Sports Behaviors of Their Mothers

\begin{tabular}{cccccc}
\hline Source & Sum of Squares & df & Mean Square & $F$ & $p$ \\
\hline gender A & 33.636 & 1 & 33.636 & 0.152 & 0.697 \\
grade B & 643.232 & 1 & 643.232 & 2.914 & 0.091 \\
A*B & 0.029 & 1 & 0.029 & 0.000 & 0.991 \\
Error & 20968.278 & 95 & 220.719 & & \\
\hline
\end{tabular}
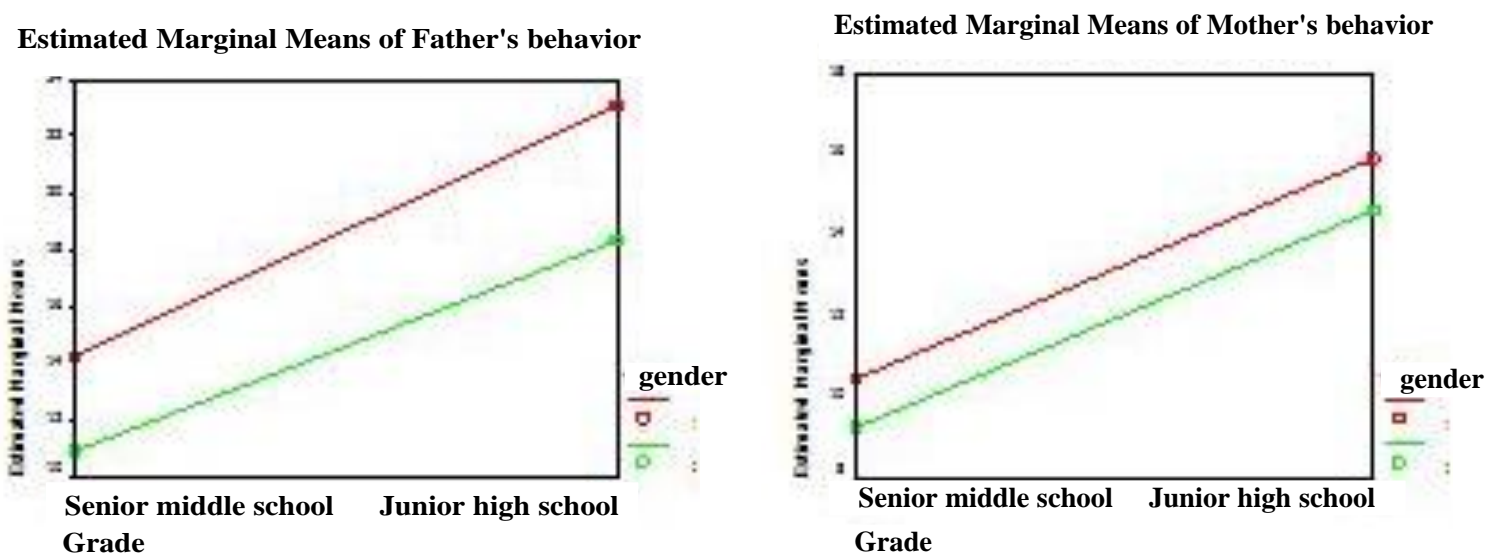

\section{Discussions}

The findings of this study show that the correlation of sports attitudes and behaviors between father and mother is significant and the correlation of sports attitudes is more significant that of sports behaviors. This, to some degree, indicates that the mutual influences of each member in the family should not be overlooked. That the correlation of sports attitudes of both parents is more significant than that sports behaviors may be determined by the different properties of attitudes and behaviors and attitudes are just a kind of state of preparation of behaviors and attitudes do not constitute behaviors. Specifically speaking, the attitude is a kind of relatively stable psychological tendency while behavior tends to be influenced by many factors and changes often, which leads to the differences of the degree of correlation.

This study shows that when teenagers are in different grades, the major effects on the sports attitudes of father and mother are striking. Through specific analysis, it has been found that the sports attitudes of parents of junior middle school students are more active than those of senior middle school students and the reasons can be attributed to the guidance effects of the current education evaluation system of junior and senior middle schools. For senior middle school students and their 
parents, such actual influences as college entrance examinations driving the focus on academic achievements, sports activities being listed as luxury items in high school education and the emphasis on diploma in human resources markets all lead to greater social and psychological pressures on them, thus significantly changing the recognition and feelings of parents for sports and dampening their positive attitudes towards sports. This study also shows that the interactive effects of the gender and grades of teenagers on the sports attitudes of their parents are striking. The sports attitude of parents of junior and senior middle school girl students is basically similar while the sports attitudes of parents of junior school boy students are more positive than those of senior middle school boy students. This result can be explained by the traditional Chinese family values. The traditional Chinese families attach more importance to the prospect and development of boys and influenced by the current evaluation system of stressing academic achievements, parents of high school boy students are influenced more and their attitudes change more greatly.

This study indicates that the major effects that different grades exert on the sports behaviors of fathers are striking while on mothers' sports behavior are not striking. Some researches show that the sports behaviors of females are obviously less than those of males. As the sports behaviors of females are on the whole not active, the differences between the sports behaviors of mothers of junior school girl students and senior school girl students are not striking; but for fathers senior middle school students, as they are faced with greater burdens and pressures, like working hard to earn tuition fees for their children, the degree of their sports behaviors are weakened.

\section{References}

[1] Peng Yongqun. The Survey on the Status of the Sports Attitudes and Behaviors of Students of Hunan University of Technology from Rural and Urban Areas, J. The Journal of Huan University of Technology ( social sciences edition),2006,26(6):111-114.

[2] Li Ying. The Survey on the Status of the Sports Attitudes and Behaviors of Middles School Students of Some Rural Areas in Hunan Province, J. the Journal of Guangzhou Sports University, 2006,26(6):111-114.

[3] Fang Shuzhen. The Discussion on the Implementation of Lifelong Sports from the Sports Attitudes and Behaviors of Adults, J. Zhongzhou Sports Shaolin and Taichi, 2009(16):30-33.

[4] Liu Feng. The Analysis of the Status of Sports Population of Changde City in 2000, J. the Journal of Huna University of Arts and Science ( natural sciences edition ),2009(16):30-33.

[5] Chen Lin. the Survey and Comparative Analysis of status of Adults Sports and Physical Exercise in Henan Province, J. Shaolin and Taichi ,2009,2(1):47-50.

[6] Qiu Qingtang Zhao Shaoxiong Wang Qun. The Analysis of Factors of Parents Influencing the Participation in Sports Activities, J. The Journal of Hunan Tax College, 2010,23(6):52-54.

[7] Li Binbin Fu Mingqiu. The Research Progress on the Family Influences on Teenagers' Participation in Sports , J. The Journal of Chengdu Sports University,2004,30(1):12-15.

[8] Tao Dagui. The Survey and Study on the Sports Behaviors of Middles School Students and the Sports Attitudes of Parents. Urban Family Education, 2011(8):152-153. 